\title{
A problemática do financiamento da saúde pública brasileira: de 1985 a $2008^{*}$

\author{
Rosa Maria Marques \\ Áquilas Mendes ***
}

\begin{abstract}
Resumo
Este artigo procura, a partir da leitura da literatura produzida no período 1985-2008, resgatar qual era o entendimento sobre as bases de financiamento do Sistema Único de Saúde (SUS) no momento da Constituição de 1988. Irá apresentar os conflitos presentes ao longo de seus vinte anos de existência, evidenciar a incerteza que cerceia seu financiamento e identificar as diferentes propostas de reordenamento de seu custeio. Sua principal conclusão é que, durante esse tempo, não foi construído um financiamento compatível com uma política de saúde universal e integral.
\end{abstract}

Palavras-chave: Financiamento do SUS; Seguridade social; Política de saúde universal.

\begin{abstract}
The financing problem of the public health service in Brazil: 1985 to 2008

Based on the specific literature concerning the period of $1985-2008$, this article attempts to look again at how SUS financing at the time when the 1988 Constitution was launched, was understood. In addition, the article presents the conflicts which took place during the first twenty years of SUS existence, as well as demonstrating the uncertainty of its financing. It also identifies the different proposals to apply its costs, arguing that, up to the present time, a solution that is compatible with a universal and complete health policy has yet to be found.
\end{abstract}

Keywords: SUS financing; Social security; Universal health policy.

JEL I18.

\section{Introdução}

A criação do Sistema Único de Saúde (SUS) em 1988, integrando o texto da então nova Constituição, compôs uma das mais importantes conquistas no campo social que os trabalhadores obtiveram no momento em que o país retomava o caminho democrático ${ }^{1}$. Isso porque, naquele momento, o Brasil estava formalmente

* Trabalho recebido em 23 de setembro de 2010 e aprovado em 25 de abril de 2011. Este artigo é parte das produções do projeto de pesquisa "Sistemas de proteção social brasileiro e cubano", financiado pelo CNPq (processo n. 620006/2008-0) e realizado pelos Programas de Pós-Graduação em Política Social (UFES), em Economia Política (PUC/SP) em Serviço Social (PUC/RS) e o Instituto Nacional de Investigaciones Economicas (Cuba).

** Professora Titular do Departamento e do Programa de Pós-Graduação em Economia e Coordenadora do Grupo de Pesquisa Políticas para o Desenvolvimento Humano da PUCSP, São Paulo, SP, Brasil. E-mail: $<$ rosamkmarques@gmail.com>.

*** Professor Doutor de Economia da Saúde da Faculdade de Saúde Pública da USP e do Departamento de Economia da PUCSP, São Paulo, SP, Brasil. E-mail: <aquilasn@uol.com.br>

(1) No momento da promulgação da Constituição de 1988, a democracia ainda não era plena. Isso ocorrerá um ano depois, com a primeira eleição livre para a presidência da República. 
criando um sistema público universal ${ }^{2}$. Assim feito, o país passou a ser o único do gênero na América Latina ${ }^{3}$ e aproximou-se da experiência de países como o Reino Unido, Suécia, Espanha, Itália, Alemanha, França, Canadá e Austrália.

Apesar do avanço que significou a criação do SUS, o Brasil está longe de dedicar a mesma atenção à saúde pública como os demais países que detêm um sistema público e universal. Para atestar essa afirmação, basta lembrar que, em 2008, enquanto o SUS gastou 3,24\% do PIB, o gasto público em saúde nos países mencionados anteriormente foi, em média, 6,7\% (Organização Mundial da Saúde WHO, 2008).

A realidade, contudo, em que esses gastos ocorrem são bastante diferentes. Nos países onde a saúde pública tem uma longa tradição - na maioria dos anteriormente mencionados -, o nível atual de comprometimento do setor público é função direta da resistência de diferentes setores da sociedade às novas normas. Estas, ao elegerem o mercado como o local privilegiado de escolhas, entendidas como otimizadas e racionais, tinham como objetivo substituir a saúde pública pelos Planos de Saúde, deixando restrita a ação do Estado nesse campo aos segmentos mais pobres da população (Anderson, 1996; Ugá, 1997).

No caso do Brasil, o SUS foi criado quando a dívida externa e a inflação elevada eram ainda um constrangimento maior e, no plano mundial, quando o ideário neoliberal e a dominância da valorização financeira começavam a dominar as relações econômicas e sociais (Chesnais, 2005) ${ }^{4}$.

No país, a propagação do pensamento neoliberal e as determinações de um de seus principais agentes, o Fundo Monetário Mundial (FMI), logo se fizeram sentir, pois o primeiro presidente eleito após o fim da ditadura militar rapidamente abraçou a agenda do Consenso de Washington e começou a propor mudanças no corpo da Seguridade Social. Exemplo disso foram os projetos de revisão constitucional encaminhados por Fernando Collor, em 1991, que propunham a eliminação das contribuições que financiavam os diferentes ramos da Seguridade Social e a restrição da cobertura pública aos segmentos mais pobres da população (Marques et al., 2009).

O SUS teve de disputar recursos com outros ramos da Seguridade Social desde o primeiro momento, quando as formas de sua implementação ainda estavam sendo elaboradas. Ao mesmo tempo, porém, em que isso ocorria, todos

(2) No período anterior, a saúde pública era voltada aos trabalhadores do mercado formal de trabalho e financiada com recursos de contribuições calculadas sobre os salários.

(3) O outro país é Cuba, que construiu seu sistema público universal como fruto da revolução socialista.

(4) A partir dos anos 1980, o capital portador de juro regressou poderoso, após o período do pós-guerra em que ficou reprimido, determinando um "novo" papel ao Estado e assegurando o pleno crescimento de sua forma parasitária e fictícia. Para Marques (2009), O Brasil não escapou a esse quadro, ficando à mercê das forças que determinaram e movimentaram o novo mundo que foi instalado com a presença definitiva dessa dominância. Para uma compreensão teórica do capital portador de juros e do capital fictício, ver Marques e Nakatani (2009). 
esses ramos enfrentavam a área econômica do governo federal para fazer valer o disposto na Constituição. Os embates por recursos financeiros para a implementação do caráter universalista da saúde são uma constante desde a criação do SUS. Os conflitos decorreram, em última análise, da força do capital portador de juros em criar um "novo consenso" em torno da supremacia do mercado em matéria de políticas sociais e em determinar as políticas macroeconômicas, regidas por metas de inflação e dívida pública restrita e/ou de superávits primários. Tanto um como outro pressionaram para a redução da participação do Estado em políticas sociais, resultando em constantes tentativas de diminuição de seus orçamentos e/ou de sua disponibilidade potencial de recursos.

No caso específico da Saúde, os vinte anos que se seguem à Constituição de 1988 são caracterizados pela tensão permanente entre dois princípios: o da construção da universalidade e o da contenção de gastos. O primeiro reafirma o direito de cidadania às ações e os serviços de saúde por meio da defesa permanente de recursos financeiros seguros. O segundo articula-se em torno da defesa da racionalidade econômica, na qual a diminuição das despesas públicas é considerada condição sine qua non de um Estado mais eficiente e menor (Friedman, 1988).

O citado conflito continua aberto e está longe de ser resolvido. Seu resultado é uma indefinição - enquanto opção efetiva da sociedade brasileira - quanto ao lugar de um sistema púbico universal nos cuidados com a saúde. Assim, deriva o fato de o SUS não ter, até o momento, conseguido definir fontes para seu financiamento.

Este artigo procura, a partir da leitura da literatura produzida no período 1985 -2008, resgatar qual era o entendimento que se tinha das bases de financiamento do SUS no momento da Constituição de 1988. Procura, também, apresentar os conflitos presentes ao longo de seus vinte anos de existência, evidenciar a incerteza que cerceia seu financiamento e identificar as diferentes propostas de reordenamento de seu custeio. Sob tal perspectiva, o artigo está estruturado em cinco partes. A primeira destaca as características do financiamento da saúde pública introduzidas pela Constituição de 1988 e do período posterior à sua promulgação. A segunda parte aponta às condições gerais que acabaram por fragilizar o financiamento do SUS, particularmente ao longo dos anos 1990. A terceira parte apresenta as diferentes propostas de reordenamento do financiamento do SUS, discutidas à luz do quadro anterior. A quarta trata tanto das incertezas que se mantiveram na aprovação da Emenda Constitucional 29, quanto das propostas de sua regulamentação e seus impasses. Por fim, são destacados os problemas da proposta de reforma tributária do governo Lula, que ameaçam os princípios sob os quais estão assentados os financiamentos da Seguridade Social e do SUS.

(5) Em alusão "invertida" ao chamado consenso keynesiano, do pós-guerra. 


\section{A construção do consenso em torno do SUS e seu financiamento}

Presente no texto constitucional em seu artigo 196, a idéia de uma saúde pública e universal foi, entre tantos outros aspectos, fruto direto da luta democrática ocorrida no país a partir de meados da década de 1970, especialmente em seus anos finais. O Movimento Sanitarista, tido na literatura especializada como o principal agente impulsionador da criação do Sistema Único de Saúde, teve surgimento ao final dos anos 1970, no momento em que diferentes setores da sociedade brasileira estavam reorganizando-se. Esse movimento, que se nutriu de discussões e elaborações anteriormente realizadas por diversos profissionais da área da saúde e das pautas reivindicatórias de oposições sindicais, teve sua expressão máxima na VIII Conferência Nacional de Saúde de 1986, quando a participação popular, a equidade, a descentralização, a universalidade e a integralidade das ações de saúde foram definidas como princípios de uma Reforma Sanitária desejável. Aos primeiros militantes do movimento - largamente formados por sanitaristas do Movimento Democrático Brasileiro (MDB) e do Partido Comunista Brasileiro (PCB) - somavamse, já há muitos anos, um número expressivo de outros, especialmente de centros e institutos de pesquisa, tais como a Fundação Oswaldo Cruz e o Centro Brasileiro de Estudos de Saúde (Cebes). Também, da burocracia responsável por administrar a política de saúde em âmbito federal e estadual ${ }^{6}$ e da Associação Brasileira de Pósgraduação em Saúde Coletiva (Abrasco) (Costa, 2002).

Dessa forma, a criação do SUS na Constituição de 1988 foi respaldada por um enorme consenso. Tecnicamente, a matéria foi aprovada no Congresso Nacional mediante a aliança de setores então tidos como de centro e de esquerda, como o Partido do Movimento Democrático Brasileiro (PMDB), o Partido da Social Democracia Brasileira (PSDB), o Partido dos Trabalhadores (PT), o Partido Democrático Trabalhista (PDT), o Partido Comunista Brasileiro (PCB) e o Partido Comunista do Brasil (PCdoB), o qual enfrentou a oposição acirrada de políticos e partidos mais conservadores - incluindo segmentos do PMDB, do Partido Trabalhista Brasileiro (PTB), do Partido Democrático Social (PDS) e do Partido da Frente Liberal (PFL), alguns deles representando interesses do setor privado da saúde 7 . Assim, foi inscrita na então nova constituição que "A Saúde é um direito de todos e um dever do Estado". A partir daí estava definida a universalização das ações e serviços de saúde, de responsabilidade do setor público, mas com o concurso do setor privado. Os demais princípios da Reforma Sanitária mencionados anteriormente também estavam garantidos ${ }^{11}$, pois integram o texto constitucional.

(6) Com a democratização do país, já no governo Sarney, lideranças do movimento sanitarista assumiram postos-chave nas instituições responsáveis pela definição e condução da política de saúde do país. Nos Estados, o mesmo já vinha acontecendo desde 1982, na medida em que eram eleitos governadores não comprometidos com o governo militar.

(7) Para a história do Movimento Sanitarista, há imensa literatura. Ver, por exemplo, Lima et al. (2005) e Escorel et al. (2005).

(8) Isso não quer dizer que sua aplicação tenha sido fácil e não tenha sofrido pressões no sentido de sua não implantação. Entre as várias contribuições sobre o assunto, ver, principalmente, Paim (1997); Fleury (1989 e 1997); Escorel (1998). 
Houve um aspecto, entretanto, negligenciado: o do financiamento. Na época, a Constituição determinava que benefícios, ações e serviços da Previdência, da Assistência e da Saúde seriam financiados com as receitas oriundas da contribuição de empregados e empregadores, da contribuição sobre o faturamento e da contribuição social sobre o lucro líquido das empresas (CSLL), bem como com parte da receita dos concursos e prognósticos e com recursos fiscais de cada esfera de governo. A Constituição, portanto, não havia criado vinculação entre um tipo de contribuição e ações de algum ramo da Seguridade, o que reforçaria, em tese, a concepção de Seguridade Social, entendida como ações e serviços que, embora relativas à Previdência, à Assistência e à Saúde, eram integrantes indivisíveis de uma mesma proteção social. Na época, essa concepção era partilhada praticamente por todos comprometidos com a saúde pública e universal. Mesmo assim, foi garantido no Ato das Disposições Transitórias que, enquanto não fosse regulamentada a lei de custeio da Seguridade Social, pelos menos 30\% do total de seus recursos deveriam ser destinados para a saúde ${ }^{9}$. Durante a Constituinte, os parlamentares, liderados pelo então deputado José Serra (naquele momento, do PMDB), recusaram-se a definir um percentual de recursos à Saúde, tal como foi feito para a Educação.

Assim, para os orçamentos de 1990 e $1991^{10}$, quando ainda não havia sido aprovada a Lei de Custeio da Seguridade Social, vigia o Ato das Disposições Transitórias (ADT). É nesse período, contudo, que se consagrou, em certa medida, a vinculação entre as principais fontes da Seguridade e suas políticas. Por acordo entre as lideranças partidárias, estabeleceu-se que os recursos do Fundo de Investimento Social (Finsocial) seriam prioritariamente destinados à saúde e a receita da CSLL seria destinada, também prioritariamente, aos programas assistenciais (Médici; Marques, 1995).

Por sua vez, a Lei de Custeio da Seguridade Social, Lei n. 8.212, de 24 de julho de 1991, reafirmou o disposto na Constituição, isto é, que o conjunto de receitas mencionado anteriormente financiaria as atividades da Seguridade Social sem vinculação entre contribuições e políticas.

Para definição dos orçamentos de 1992 e 1993, quando já vigia a Lei 8.212, os recursos destinados para cada política foram frutos de negociação, observada a vinculação prioritária informal, como foi mencionado. Para 1992, o orçamento previa o repasse de $25 \%$ das receitas de contribuições de empregado e empregador para a área da saúde; para 1993, o percentual do repasse previsto já havia se reduzido para $15,5 \%$

(9) No período 1980 - 1990, as contribuições de empregados e empregadores representaram $80 \%$ do total de recursos que financiavam o gasto com saúde pública federal. Antes da criação do SUS, o gasto era, com exceção de algumas ações e serviços, voltado à saúde dos trabalhadores do mercado de trabalho formal inscritos na Previdência.

(10) Não se faz referência ao orçamento de 1989 porque este foi aprovado em 1988. Da mesma forma, embora a Lei 8.212 tenha sido aprovada em 1991, o orçamento do ano seguiu o inscrito no Ato das Disposições Transitórias, pois foi aprovado em 1990. 


\section{A fragilidade do fnanciamento do SUS fca exposta}

Em maio de 1993, quando a Previdência Social parou de repassar ao Ministério da Saúde (MS) o correspondente a 15,5\% da arrecadação da contribuição de empregados e empregadores, o mecanismo de financiamento da saúde que havia sido praticado até então mostrou toda sua fragilidade.

A atitude assumida pelo então Ministro da Previdência, Antônio Britto, foi provocada pelo aumento expressivo do gasto com benefícios decorrentes da regulamentação dos novos direitos introduzidos pela Constituição de 1988. Ao final do ano, a Previdência Social registrou um superávit que corresponderia a apenas 4,3 meses de repasse para a Saúde. Caso a Previdência tivesse efetuado a transferência de $15,5 \%$ da arrecadação das contribuições de empregados e empregadores, ela teria encerrado o ano com um déficit expressivo. Assim, não há dúvida de que a decisão de cessar o repasse foi política: a situação financeira da esfera previdenciária era apresentada como relativamente estável posto serem as contribuições suficientes para arcar com os benefícios e a Saúde era apresentada à opinião pública como em meio a uma crise de financiamento. A postura de considerar a receita de contribuições de empregados e empregadores de uso exclusivo da Previdência Social facilitou a vinculação legal introduzida pela reforma promovida por Fernando Henrique Cardoso em 1995, por meio da proposta de emenda constitucional ${ }^{11}$. Para dar conta da urgente necessidade de financiamento da Saúde, o governo federal, presidido por Itamar Franco, precisou decretar novamente estado de calamidade pública, o que permitiu ao MS demandar novo empréstimo junto ao Fundo Amparo ao Trabalhador $(\text { FAT })^{12}$.

Tais fatos tiveram o mérito de evidenciar que os mecanismos de financiamento do SUS continuavam indefinidos e o volume de recursos com que ele podia contar era instável. A partir disso e aproveitando a discussão da Revisão Constitucional (logo adiada), várias propostas começaram a contemplar a questão do financiamento do SUS. Quase todas procuravam aumentar o volume e dar maior estabilidade aos recursos destinados à Saúde. Algumas delas adotavam como estratégia, a especialização ou vinculação das fontes dentro da Seguridade Social (Piola, 1994).

Enquanto novas propostas de financiamento para o SUS eram discutidas, o governo federal desferiu um profundo golpe no conjunto da Seguridade Social, desvinculando parte de seus recursos (Médici; Marques, 1994; Afonso et al., 1995).

No bojo do Plano Real, (conjunto de medidas implementadas para debelar a_elevada inflação crônica brasileira), ficou definido que $20 \%$ da arrecadação das

(11) Após um longo processo de tramitação no Congresso Nacional, em 1998, foi possível a obtenção do acordo para a aprovação da Emenda Constitucional n. 20.

(12) No ano anterior, o Ministério já havia tomado empréstimo junto ao FAT, em decorrência do número de ações contra o recolhimento da Contribuição para o financiamento da Seguridade Social (Confins) e da CSLL. A Cofins substituiu o Fundo de Investimento Social (Finsocial) em 1991. 
contribuições sociais ficariam disponíveis para uso do governo federal. Essa medida foi assegurada pela criação do Fundo Social de Emergência, renomeado Fundo de Estabilização Fiscal em 1997 e, finalmente, Desvinculação das Receitas da União (DRU) em 2000. Esses recursos, antes de uso exclusivo da Seguridade Social, podiam, agora, ser alocados para qualquer fim, inclusive para pagamento dos juros da dívida (Mendes; Marques, 2009).

Sentiu-se a diminuição da disponibilidade de recursos para a proteção social, principalmente, na área da Saúde. Isso porque os recursos necessários para o pagamento dos benefícios previdenciários não podiam (e não podem) faltar, na medida em que derivam de direitos individuais, não passíveis de questionamento. $\mathrm{O}$ fato não significou, contudo, que tenha havido diminuição do volume alocado para o SUS, pois, ao mesmo tempo em que houve restrição quanto aos recursos de origem federal, aumentaram aqueles das outras instâncias, especialmente dos municípios.

\section{Na busca de soluções para o fnanciamento do SUS}

No caso das propostas de especialização das fontes, era sugerido que a contribuição sobre o salário fosse de uso exclusivo da Previdência e que o Finsocial (ou de outra fonte que viesse substituí-lo) fosse destinado ao SUS. Havia, também, a proposta de definir alíquotas, no interior de cada fonte, que estivesse associada cada política da Seguridade Social, isto é, à Previdência, à Saúde e à Assistência. Por último, havia a proposta de definir um percentual do total das receitas da Seguridade, para a Saúde ${ }^{13}$.

$\mathrm{Na}$ época, duas emendas relativas ao financiamento da Saúde foram formalmente apresentadas à Revisão Constitucional. A primeira delas, de iniciativa do Deputado Chafick Farah, estabelecia que a União aplicaria no SUS, anualmente, nunca menos do que $18 \%$ da receita de imposto e contribuições. A segunda - de autoria dos deputados Waldir Pires e Eduardo Jorge - propunha que os recursos destinados à Saúde correspondessem a, pelo menos, 30\% do total dos recursos da Seguridade Social, acrescidos de mais $10 \%$ da receita de impostos do governo federal. Essa Proposta de Emenda Constitucional 169 (PEC 169/1993) introduzia, a título de sugestão, a ideia de que as demais esferas de governo destinassem à Saúde ao menos $10 \%$ de seus recursos ${ }^{14}$. Estimativas do Ministério da Saúde - considerando que a receita da União a qual se aplicariam os percentuais era a receita líquida, isto é, deduzidas das transferências para os Estados e Municípios de parte da arrecadação do Imposto de Renda e do Imposto sobre Produtos Industrializados (IPI) e não

(13) As propostas para o financiamento do SUS que são apresentadas a seguir apoiam-se em Marques e Mendes (1999).

(14) O relator da PEC 169, deputado Darciso Perondi, do PMDB, modificou a proposta original, definindo que os recursos a servirem de base para o cálculo dos $10 \%$ da participação da União deveriam compreender as transferências constitucionais. Fez isso ao substituir, na redação, "impostos" por "impostos e transferências". 
incluindo a receita do Programa de Integração Social e Programa de Formação do Patrimônio do Servidor Público (PIS/Pasep) - apontavam que a proposta de Chafick Farah corresponderia a $1,88 \%$ do PIB, o equivalente a 54 dólares per capita/ano. No caso da emenda de Waldir Pires e Eduardo Jorge, os recursos atingiriam 2,66\% do PIB, ou seja, 65 dólares per capita/ano.

Por sua vez, o Conselho Nacional de Secretários de Saúde (Conass) assumia como sua a proposta dos deputados Waldir Pires e Eduardo Jorge, incorporando a destinação de 10\% das receitas dos Estados e Municípios. Além disso, fazia mais nove proposições: i) a incorporação nas receitas da Seguridade dos 40\% da arrecadação do PIS/Pasep que era (e ainda é) destinado ao BNDES, ii) a unificação da Cofins e do PIS/Pasep (a uma alíquota de 2\%, da qual 0,65\% seria destinado ao seguro desemprego ${ }^{15}$ ), iii) a aplicação da CSLL às instituições financeiras, iv) a redefinição do FAT, na medida em que a saúde passaria a ser um de seus objetivos, v) a sobretaxa do cigarro, das bebidas alcoólicas e de outros produtos prejudiciais à saúde, vi) o fim das isenções de imposto de renda das empresas que prestavam assistência médica a seus funcionários, vii) a extinção, no curto prazo, da dedução no imposto de renda da pessoa física a respeito dos pagamentos aos planos privados de previdência e saúde, viii) a exigência do reembolso dos gastos efetuados por segurados de Planos de Saúde junto ao SUS, ix) a exigência de a União efetuar o pagamento, com recursos próprios, de seus encargos previdenciários entre outras. Esse conjunto de proposições fazia parte de projeto maior de uma reforma tributária, na qual os Estados e Municípios elevariam sua participação na partilha da arrecadação de impostos de $29 \%$ para $35 \%$, no caso dos Estados, e de $17 \%$ para $40 \%$ no caso dos Municípios. No caso da Saúde, o resultado da nova partilha seria que à União caberia somente a regulação e normalização de abrangência nacional, exigindo a unificação das estruturas existentes. Em 1993, o Conselho Nacional de Saúde assume a proposta de financiar a Saúde com 30\% dos recursos da Seguridade Social e 10\% da receita de impostos da União, do Distrito Federal, de Estados e Municípios.

Tendo em vista o debate que se fazia em torno do financiamento do SUS, todos os candidatos à presidência da República, nas eleições de 1994, contemplaram esse assunto em seus programas ${ }^{16}$. No programa do PT, no item "Diretrizes de Governo", os principais pontos eram: i) recuperar, já no primeiro orçamento, o nível histórico de recursos alocados em Saúde e aumentar progressivamente seu volume de modo a atingir 5\% do PIB, o que equivaleria a 150 dólares per capita/ano; ii) os recursos seriam compostos de $30 \%$ das receitas da Seguridade Social, da extinção gradativa da renúncia fiscal decorrente da dedução dos gastos com planos de saúde e

(15) Essa proposta tinha claramente a intenção de dar fim à contestação por parte dos empresários da existência de duas contribuições com a mesma base fiscal.

(16) Somente as propostas do PT e do PSDB são analisadas na medida em que tiveram as candidaturas as mais expressivas em termos de votos. 
similares no imposto de renda ${ }^{17}$ e de $10 \%$ das receitas dos Estados e Municípios, o que seria viabilizado mediante acordo. Note-se que a proposta reproduzia o conteúdo da PEC169/1993.

Já, o programa do PSDB comprometia-se com "Aumentar e garantir a estabilidade dos recursos públicos para a saúde", o que seria obtido mediante: i) aplicação de, no mínimo, R\$ 80,00 per capita/ano; ii) estímulo ao incremento dos gastos de Estados e Municípios, por meio de sistema de financiamento compartilhado; iii) transferência global de recursos, sem vinculações predeterminadas, diretamente do Fundo Nacional de Saúde para os Fundos Estaduais e Municipais de Saúde; estabelecimento de mecanismos e critérios redistributivos para a transferência de recursos materiais e financiamento entre regiões e grupos sociais em situação de exclusão.

Ainda em 1994, são apresentadas mais duas propostas, a do deputado José Pinotti, do Partido Socialista Brasileiro e a do deputado Carlos Mosconi (PSDB). José Pinotti sugeria um gasto em Saúde equivalente a 5\% do PIB anterior. Essa proposta, que não foi acompanhada de sua operacionalização, elevaria em 136\% o gasto em Saúde. Já, Carlos Mosconi vinculava toda a arrecadação da Cofins e da CSLL das empresas à Saúde. O relator de tal proposta, deputado Urcisino Queiroz, do Partido Frente Liberal, assim denominado na época - desde 2007 DEM (Democratas) -, além de atribuir uma vinculação progressiva dessas contribuições à Saúde, com um máximo de $64 \%$ no lugar de sua integralidade, incorporou a Contribuição Provisória sobre a Movimentação Financeira (CPMF), resgatando proposta anterior do então Ministro Adib Jatene ${ }^{18}$. A proposta modificada pelo relator tomou o nome de PEC 82 - A/ 1995. Essa mesma proposta assumiu o nome de PEC 29, em 2000, quando foi enviada para o Senado.

Em 1998, durante o II Encontro Nacional de Conselheiros de Saúde, o então Ministro da Saúde, José Serra, apresentou a seguinte proposta: i) 30\% dos recursos da Seguridade Social, excluída a receita do PIS/Pasep ${ }^{19}$; ii) continuidade da CPMF, mas financiando o conjunto da Seguridade e não apenas a Saúde; iii) vinculação progressiva da Cofins e da CSLL (de 60\% em 1999, chegando a 70\% em 2003; iv) vinculação progressiva da receita de impostos e transferências dos Estados e Municípios, iniciando com 8\% em 1999 e chegando a 12\% em 2003, no caso dos Estados; e iniciando com 11\% em 1999 e chegando a 15\% em 2003, no caso dos Municípios.

(17) Essa proposta não seria nunca mais explicitada em programa do PT, dada a rejeição encontrada junto aos setores da chamada "classe média".

(18) A CPMF passou a vigorar em 23 de janeiro de 1997. Substitui o Imposto Provisório sobre Movimentação Financeira criado em 13 de julho de 1993, mas que vigorou a partir de primeiro dia de 1994.

(19) A receita do PIS/Pasep destina-se ao FAT que, além do abono, paga o seguro desemprego. José Serra foi o autor dessa proposta durante os trabalhos da Constituinte. 
Frente a isso, o Conselho Nacional de Saúde procurou reunir o conteúdo da PEC 82 - A/1995 e da proposta do Ministro José Serra. Desse modo, passou a defender: i) 30\% dos recursos da Seguridade; ii) a integralidade da arrecadação da CPMF; iii) a progressividade na vinculação da Cofins e na CSLL, mas com $80 \% \mathrm{em}$ 2003; iv) vinculação de percentuais iguais para Estados e Municípios, de 7\% em 1999 e de $13 \%$, em 2003.

\section{Defnindo consensos: um passo à frente, um passo atrás}

Em outubro de 2000, finalmente a Emenda Constitucional 29 (EC 29) foi aprovada. Segundo seu texto, no primeiro ano de vigência, os estados e municípios deveriam alocar, ao menos, $7 \%$ das receitas de impostos e transferências constitucionais, sendo que esse percentual precisaria crescer anualmente até atingir, aos estados, 12\% em 2004 e, aos municípios, 15\%. À União, definia, para o primeiro ano, o aporte de, ao menos, 5\% em relação ao orçamento empenhado do período anterior; para os seguintes, o valor apurado no ano anterior seria corrigido pela variação do PIB nominal. Em relação à União, a EC 29 não explicita qual é a origem dos recursos e, em relação à Seguridade, é omissa, esquecendo toda a discussão realizada anteriormente e como se não houvesse disputa pelos recursos da Seguridade Social.

A aprovação da EC 29 foi, sem dúvida, um avanço na definição das fontes de financiamento do SUS, pois, além de definir a participação de cada esfera de governo, garantia um mínimo de recursos (Favaret et al., 2001). Os conflitos, contudo, não se fizeram tardar, obstaculizando sua automática e plena aplicação.

Em nível da União, o texto da EC 29 deu origem à acirrada discussão entre o Ministério da Saúde e o da Fazenda a respeito da base de cálculo a ser utilizada para a previsão mínima de recursos: o conflito "base móvel" versus "base fixa". $\mathrm{Na}$ interpretação do MS, o ano-base, para efeito da aplicação do adicional de 5\%, seria o de 2000 e o valor apurado para os demais anos, sempre o do ano anterior, ou seja, calculado ano a ano, daí ser chamado de "base móvel". Para o Ministério da Fazenda, contudo, o ano-base seria o de 1999, somente acrescido das variações nominais do PIB ano a ano, denominado "base fixa". Essa diferença de interpretação resultava já no orçamento de 2001, em R\$ 1,19 bilhão, o que permitiria, por exemplo, a duplicação dos recursos do Programa Agentes Comunitários em relação a 2000. A Advocacia Geral da União (AGU) deu ganho de causa ao Ministro Malan (Fazenda), que também contava com o apoio do Ministério do Planejamento - órgão fundamental, com poder de orientação aos vetos presidências à Lei de Diretrizes Orçamentárias (LDO) e à Lei Orçamentária. Tal discussão teve prosseguimento, 
perpassando os primeiros anos do governo Lula ${ }^{20}$. Somente na metade de 2005, o Tribunal de Contas da União (TCU), por meio de seu Acórdão n. 957/2005, considerou oficialmente a "base móvel" como o método apropriado para o cálculo do piso mínimo de aplicações em ações e serviços de saúde. Na maior parte das vezes, uma decisão do TCU é acatada pelo executivo federal, porém, até o momento, não há nada que indique a existência de uma decisão definitiva do governo Lula a esse respeito.

No caso dos Estados, a aplicação da EC 29 ampliaria sua participação no custeio, pois, em geral, eles destinavam $6 \%$ de sua receita em 2000 . Nos anos, contudo, que se seguiram o cumprimento do disposto na emenda tem sido difícil. Isso porque há Estados que não só não destinam os recursos conforme o percentual definido pela EC 29, mas também consideram gasto em saúde despesas alheias a essa política, como o pagamento de inativos, os gastos com empresas de saneamento, habitação urbana, recursos hídricos, merenda escolar, alimentação de presos, hospitais de "clientela fechada" (como hospitais de servidores estaduais). Tudo isso a despeito da existência de parâmetros claros e acordados entre o Ministério da Saúde, os Estados e seus tribunais de contas para a definição de despesas de ações e serviços de saúde. Dessa forma, mediante "artifícios", os Estados desconheceram esses parâmetros e incluíram gastos alheios à saúde para atingirem sua meta ${ }^{21}$.

Já, para os Municípios, tanto das capitais como do interior, a vinculação realizada pela EC 29 não chegaria a alterar seu comprometimento, pois a destinação de recursos sempre foi elevada. O único senão é que alguns municípios, principalmente os grandes, tais como Estados, registram a despesa com inativos como se fosse gasto em saúde.

(20) Em 2004, a Mensagem do Presidente ao Projeto de Lei Orçamentária 2004 ao Congresso assumia o critério de "base móvel", de acordo com uma simples manifestação favorável do Tribunal de Contas da União. Já, na LDO 2005, tal critério foi vetado pelo presidente, assim como havia ocorrido na LDO 2003. Desse modo, o critério da "base fixa" voltou a ser introduzido como orientador da Lei Orçamentária (Ribeiro, Piola, Servo, 2007).

(21) Para agilizar a aplicação da EC 29, o Conselho Nacional de Saúde, em conjunto a outras entidades, elaborou o documento "Parâmetros consensuais sobre a implementação e regulamentação da EC29". A partir daí, o MS promoveu, entre setembro de 2001 e setembro de 2002, três seminários com os tribunais de contas da União, a comissão de Seguridade Social da Câmara e do Senado, o Conselho Nacional de Secretários de Saúde (Conass) e o Conselho Nacional dos Secretários de Saúde (Conasems). Esses seminários visavam a construir uma interpretação homogênea e assegurar os objetivos que motivaram a aprovação da emenda. Depois de um intenso debate, foi aprovada, pelo Conselho Nacional de Saúde, a resolução n. 316, de 4 de abril de 2002, substituída depois pela resolução n. 322, de 8 de maio de 2003, a qual foi homologada pelo Ministro da Saúde. Essa última Resolução, então, ao dispor sobre dez diretrizes a respeito dos temas abordados no âmbito dos Seminários, constituiu-se no grande instrumento-chave do consenso entre as entidades ligadas à saúde e na peça principal de orientação para o projeto de regulamentação da EC 29. Para finalizar os encaminhamentos pró-regulamentação da EC 29, durante o ano de 2003, foram realizados em Brasília mais dois seminários, promovidos pela Câmara Técnica do Sistema de Informações sobre Orçamentos Públicos em Saúde SIOPS e pela Comissão para Elaboração de Proposta de Lei Complementar (PLC) do Ministério da Saúde, onde foi intensa a discussão das entidades presentes. 
De qualquer forma, a avaliação permitiu à aprovação da EC 29 que o gasto SUS aumentasse de 2,89\% do PIB, em 2000, para 3,67\% do PIB, em 2008, ainda insuficiente para ser universal e garantir o atendimento integral. Como mencionado, todavia, na Introdução deste artigo, o gasto público brasileiro é baixo em relação ao dos demais países que têm um sistema público universal. Para que o Brasil atingisse o nível de tais países, precisaria dobrar a participação do SUS em relação ao PIB. Além disso, segundo a Organização Mundial da Saúde, a participação do gasto público no total da despesa com saúde também é baixo no país: cerca de $44,1 \%$. Nos demais países, o percentual é, em média, $80 \%{ }^{22}$. No caso brasileiro, ainda, é significativo o incentivo concedido pelo governo federal à Saúde privada, na forma de redução de imposto de renda a pagar da pessoa física ou jurídica, o que é aplicada sobre despesas com Plano de Saúde e/ou médicas e similares (Piola, 2009).

A operacionalização da EC 29 está pendente desde 2003, provocando perda de recursos para o SUS e enfraquecimento do consenso obtido. Segundo informações do Sistema de Informações sobre Orçamento Público em Saúde (Siops), mais da metade dos Estados não tem cumprido o disposto na EC 29, o que impediu o ingresso de R\$ 3 bilhões anuais para o SUS. No caso da União, a diferença entre o valor mínimo previsto e o efetivamente aplicado entre 2000 e 2008 chega também a R 3 bilhões. Se a isso se soma montante cancelado de Restos a Pagar, de R \$ 2,6 bilhões, e se os gastos registrados indevidamente como SUS forem subtraídos tais como Bolsa Família, ações e serviços de saúde para servidores e Farmácia Popular, a diferença atinge R $\$ 6$ bilhões (Piola, 2009).

A regulamentação da EC 29 não é prioridade no governo Lula. Isso porque a política macroeconômica implementada durante os dois governos Lula, ao dar prosseguimento ao que era feito por Fernando Henrique Cardoso, tinha objetivo central o cumprimento de metas de inflação e a obtenção de elevados superávits primários, resultando em constante pressão para que o gasto público fosse diminuído, o que, no SUS, assumiu a forma de contingencionamento. A inclusão da EC 29 na pauta do Congresso, em abril de 2006, deveu-se tão somente à ação da Frente Parlamentar da Saúde. A matéria continua a enfrentar dificuldades para sua aprovação, no momento em que este artigo está sendo escrito (agosto de 2010).

O interesse do governo em relação à EC 29 somente se manifestou quando da discussão sobre a continuidade da CPMF, ao final de 2007. Nessa oportunidade, ele apresentou uma contraproposta ao $P L P 01 / 2003^{23}$ em que, no lugar de garantir para a Saúde um percentual mínimo das receitas de seu âmbito, propunha um acréscimo

(22) Na Alemanha, o percentual é 76,9\%; no Reino Unido, 87,1\%; Suécia, 81,7\% e na Espanha, 71,4\%.

(23) Dentre os principais itens do projeto de regulamentação da EC 29 (PLP 01/2003), de autoria do então deputado Roberto Gouveia (PT/SP), destacam-se dois: i) a modificação da base de cálculo para a vinculação dos recursos da União, passando do valor apurado no ano anterior corrigido pela variação do PIB nominal para $10 \%$, no mínimo, de sua Receita Corrente Bruta; ii) a definição das despesas que devem ser consideradas como ações e serviços de saúde e daquelas que não se enquadram nesse conceito. 
escalonado da participação da CPMF em seu financiamento. Pensava o governo que essa imbricação entre a continuidade da CPMF e o financiamento da Saúde iria assegurar a prorrogação dessa contribuição. Mas já que o Senado não aprovou a CPMF, a proposta do governo não teve prosseguimento ${ }^{24}$.

Em abril de 2008, projeto similar ao PLP n. 01/2003 da Câmara, no Senado — PLS n. 121/2007 —, foi aprovado com modificações importantes. A fórmula de cálculo para aplicação do governo federal de no mínimo de $10 \%$ da Receita Corrente Bruta (RCB) foi alterada por meio da criação de um escalonamento ao longo de quatro anos, sendo que seriam aplicados $8,5 \%$ dessa receita no primeiro ano, passando para $9 \%$ no ano seguinte e $9,5 \%$, e $10 \%$ nos seguintes, respectivamente. Mas sua aplicação resultaria no aumento do gasto SUS de menos de 1\% do PIB. Para se ter uma idéia, se esse PLS n. 121/2007 fosse considerado, os recursos para a saúde pública seriam elevados de $\mathrm{R} \$ 58,3$ bilhões (gasto MS executado em 2009) para R \$ 77,6 bilhões (8,5\% da RCB), no orçamento de 2010, isto é, 15,1 bilhões a mais da dotação atualizada desse ano (R\$ 62,5 bilhões) (Carvalho, 2010).

O projeto de regulamentação da EC 29 (PLS 121/2007) foi para aprovação na Câmara sob uma nova denominação: PLP 306/2008. Ao receber esse Projeto, a Câmara encaminhou um substitutivo global a ele, no qual novamente introduzia a correção dos recursos da União pela variação nominal do PIB. Ademais, resgatou a idéia de uma CPMF, porém agora como CSS - Contribuição Social para a Saúde -, isto é, com a mesma base tributária que a CPMF, só que com alíquota de $0,10 \%$ e não mais $0,38 \%$. Segundo avaliação do Conselho Nacional de Saúde (CNS), se a CSS fosse aprovada, sua arrecadação estimada seria de R\$ 12,5 bilhões. Ainda segundo o CNS, desse montante, porém, seria necessário subtrair $20 \%$ da DRU e os R\$ 6 bilhões devidos ao Fundo de Manutenção e Desenvolvimento da Educação Básica (previsto no projeto). Desse modo, o orçamento do MS de 2010 passaria de $\mathrm{R} \$ 62,5$ bilhões para R \$ 66,5 bilhões, bastante inferior ao projeto do Senado (PLS 121/2007) (Ibid).

O projeto da Câmara PLP 306/2008 foi votado no primeiro semestre de 2008, ficando apenas na dependência da votação de um destaque que retira do texto a CSS, sob a justificativa da oposição ao governo Lula que se trata do retorno da CPMF. Se esse destaque permanecer e não for derrubado, o projeto será inócuo, pois inviabiliza a criação da CSS e, sem ela, retorna-se à situação atual: sem nenhum acréscimo de recurso para a saúde.

Ambos os projetos, o do Senado (PLS 121/2007) e o da Câmara (PLP 306/2008), embora divergentes quanto ao financiamento do SUS (em relação ao

(24) O PLP 01/2003 foi aprovado na Câmara e enviado ao Senado, onde foi aprovado. Como essa aprovação contava, porém, com os recursos da CPMF, ele deixou de ser viável. A alocação de $10 \%$ da Receita Corrente Bruta da União para a Saúde, prevista no texto inicial do projeto, foi retirada no último momento, quando de sua aprovação na Câmara e mantida a forma de cálculo anterior, além de contemplar recursos da CPMF. 
montante e à forma de cálculo), têm em comum o fato de definirem, de forma inequívoca, quais despesas devem e não devem ser consideradas como ações e serviços de saúde. Ademais, ambos contemplam os mesmos instrumentos de transparência e visibilidade na gestão da saúde e critérios de transferências federais para estados e municípios e de estados para municípios.

Independentemente de a CSS ser aprovada ou não, a matéria terá, obrigatoriamente, de retornar ao Senado, pois a Câmara alterou o texto aprovado anteriormente pelo Senado. Os senadores, ao receberem o Projeto para nova votação, terão as seguintes opções: i) aprovar as mudanças feitas pela Câmara, mantendo a correção do orçamento da saúde de acordo com a variação nominal do PIB (com ou sem a CSS), ii) votar o texto do Senado, com a fórmula escalonada das receitas correntes brutas, iii) votar novo texto.

Enquanto a operacionalização da EC 29 não avança e as propostas mencionadas continuam em discussão, em diversas oportunidades o executivo propôs encaminhamentos que, caso fossem implementados, levariam à redefinição do financiamento do conjunto das políticas que integram a Seguridade Social. Esse foi o caso da proposta de Reforma Tributária encaminhada pelo governo Lula ao final de 2008, que previa a extinção de todas as contribuições.

\section{A ofensiva do executivo coloca em risco o SUS e a seguridade social}

A proposta de reforma tributária do governo Lula, apresentada ao final de 2008, sem dúvida, constituiu a pior ameaça aos direitos sociais introduzidos pela Constituição de 1988, particularmente sobre o sistema da Seguridade Social, mas também para as áreas de educação e trabalho. A proposta tinha como propósito, simplificar o sistema tributário e desonerar os investimentos produtivos e a folha de salários $^{25}$.

No âmbito da União, essa reforma propunha a agregação dos impostos e extinção das contribuições sociais e econômicas que possuem semelhanças em sua base de incidência. Em nível dos estados, a emenda constitucional propunha que o imposto sobre circulação de produtos e serviços (ICMS) passasse a ser de competência conjunta dos Estados, reduzindo a autonomia da administração tributária das unidades federadas.

Quanto às contribuições sociais, seriam extintos o PIS, a Cofins e a Contribuição para o Salário Educação, dando lugar ao Imposto sobre valor Adicionado Federal (IVA). Já, a CSLL e o Imposto de Renda seriam unificados,

(25) Esses objetivos tornam essa proposta muito semelhante a outras apresentadas por setores tidos como neoliberais. Um de seus fundamentos teóricos é o de considerar que o investimento e a contratação de mão de obra são determinados por seus custos. Mesmo em leituras convencionais, apoiados em Keynes, esse pressuposto não encontra eco. 
gerando um Imposto de Renda mais amplo ${ }^{26}$. O projeto previa, ainda, a desoneração da contribuição patronal sobre a folha de pagamento, por meio de legislação específica, após as devidas alterações constitucionais.

Assim, a reforma tributária afetaria diretamente o financiamento da Seguridade Social, do Fundo de Amparo ao Trabalhador (FAT) e da educação básica (Salário-Educação). Os três tributos mais relevantes para a Seguridade Social seriam alterados. Em sua substituição, caberia à Seguridade Social $39,7 \%{ }^{27}$ do produto da arrecadação dos impostos sobre renda (IR), dos produtos industrializados (IPI) e das operações com bens e prestações de serviços (IVA-F), o que seria insuficiente à realização de suas ações e serviços, bem como ao pagamento de benefícios ${ }^{28}$.

Desse modo, a Seguridade Social deixaria de contar com recursos a ela exclusivos (mesmo considerando que 20\%, da DRU, foram dela desvinculados) e o financiamento de seus ramos, principalmente do SUS, dependeria de uma partilha da arrecadação do IVA-F e das contribuições previdenciárias (enquanto essas ainda existissem). E a história recente de disputa por recursos entre as áreas econômica e social indica quão difícil serão as negociações dessa partilha.

\section{Considerações finais}

Desde a criação do SUS, que considera a saúde um direito universal, de responsabilidade do Estado, seu financiamento não foi resolvido. Durante os anos de sua existência, um de seus maiores desafios tem sido conseguir os recursos necessários para preservar o caráter universal de seu acesso e garantir seu atendimento integral. A carência de recursos adequados sistematicamente coloca em questão a qualidade de suas ações e serviços e fomenta o argumento daqueles que entendem a saúde pública como aquela que se dedica ou somente à Atenção Básica ou dirigida apenas aos segmentos mais pobres da população (mesmo que envolvendo os serviços de Alta Complexidade).

Como visto ao longo deste artigo, na ausência de definição de fontes para o custeio do SUS, esta área fica ao sabor de duas restrições: i) a prioridade, no interior da Seguridade Social, da destinação de recursos para a Previdência Social, ii) as restrições derivadas de uma política econômica voltada para garantir metas de inflação e superávits primários elevados.

(26) Aqui, foram mencionados apenas os aspectos que alterariam os impostos e as contribuições em vigor. Para maiores detalhes da proposta, ver www.nossareformatributaria.com.br.

(27) Esse percentual foi comunicado pelo relator da reforma tributária, Deputado Sandro Mabel, quando da apresentação de seu substitutivo em Seminário realizado no Centro de Extensão Universitária, em São Paulo, em 13 de março de 2009.

(28) Para 2007, isso significaria que a Seguridade Social perderia R \$ 43,6 bilhões (os recursos da DRU já estariam deduzidos) (Carvalho, 2009). 
A área da Saúde tentou, ao longo de todos os anos que se seguiram à promulgação da Constituição de 1988, construir consensos que permitissem garantir recursos adequados para a implementação de um sistema público universal. 0 compasso de espera da regulamentação da Emenda Constitucional 29 está, contudo, colocando em risco a manutenção de parte desses consensos e isso atesta o fato de que mais da metade dos Estados não está cumprindo o que nela está previsto. Ademais, as tentativas realizadas durante o primeiro governo Lula de incluir como despesa do Ministério da Saúde itens não reconhecidos como gastos SUS indicam que o governo federal não assume o texto previsto da regulamentação da EC 29 e não está disposto a aumentar sua participação no gasto com saúde. Soma-se a isso a última proposta de reforma tributária encaminhada que, se implementada, alteraria totalmente os marcos sob os quais se foram construídos a Seguridade Social e o SUS.

Para além das ações das diferentes gestões presidencias, porém, é preciso reconhecer que o SUS foi criado sem ter havido, de fato, a opção de priorizar um sistema público por ser incompatível com a permanência dos incentivos aos cuidados com a saúde privada, presentes no sistema tributário do país. Para que sejam garantidos recursos adequados ao financiamento de uma saúde pública universal, tal como estabelecida na Constituição de 1998, seria preciso, então, ocorrer uma nova "Reforma Sanitária", que redefinisse o SUS como o principal agente dos cuidados com a saúde.

Enquanto o arranjo político necessário para isso não acontece - o que exigiria, além do fim das deduções do imposto de renda das despesas com saúde, que os sindicatos de trabalhadores aderissem ao SUS e deixassem de reivindicar Planos de Saúde - a luta por recursos adequados, por mais necessária que seja, terá sempre alcance bastante limitado e fadado a sofrer retrocessos. É o que atesta tanto o conteúdo das propostas de financiamento discutidas durante a segunda metade dos anos 1990 e das atualmente em pauta, como seus encaminhamentos. Para dobrar o gasto público em saúde de modo a atingir nível condizente com a média dos demais países que têm sistema similar, seria preciso mais do que simplesmente obter aumento de recursos mediante barganha, seria necessário elevar o SUS à condição de prioridade entre as políticas de governo.

Uma via para isso ser construído seria manter o financiamento da Seguridade Social como na Constituição, estabelecendo um percentual de alocação para a saúde e definindo uma responsabilidade de aplicação dos impostos para as três esferas de governo, em especial à União e aos Estados, que atualmente não seguem o disposto na EC 29. A isso se somariam os recursos oriundos de novas fontes, tais como as transações financeiras e fim das deduções do IRFF e Imposto de Renda da Pessoa Jurídica (IRPJ) para as despesas de saúde. 


\section{Referências bibliográficas}

AFONSO, José Roberto; CARVALHO, Luiz de Gonzaga; SPÍNDOLA, Lytha. Fundo Social de Emergência: intenções e feitos. São Paulo: Fundação do Desenvolvimento Administrativo. Instituto de Economia do Setor Público, maio 1995. 11p. tab. (Notas Técnicas IESP, 11).

ANDERSON, Perry. Balanço do neoliberalismo. In: A. BORÓN, As políticas sociais e o estado democrático. Rio de Janeiro: Paz e Terra, 1996.

CONSELHO NACIONAL DE SAÚDE. Ata da ducentésima reunião ordinária do Conselho Nacional de Saúde - CNS. Brasília, 2009. Disponível em <http://conselho.saude.gov.br/>. Acesso em: 8 set. 2010.

CARVALHO, Gilson. Financiamento da saúde no Brasil: Conjuntura 2009. In: CONGRESSO BRASILEIRO DE SAÚDE COLETIVA, 9, Recife, Abrasco, nov. 2009.

Regulamentação da EC-29: a perspectiva inicial da PEC 169 e a realidade dos atuais projetos de regulamentação. Ago. 2010. Mimeografado.

COSTA, Ricardo César da Rocha. Descentralização, financiamento e regulação: a reforma do sistema público de saúde no Brasil durante a década de 1990. Revista de Sociologia e Política, n. 18, p. 49-71, jun. 2002.

CHESNAIS, François. O capital portador de juros: acumulação, internacionalização, efeitos econômicos e políticos. In: CHESNAIS, F. (Org.). A finança mundializada, raizes sociais e políticas, configuração, consequências. São Paulo: Boitempo, 2005.

ESCOREL, Sarah. Reviravolta na saúde: origem e articulação do movimento sanitária. Rio de Janeiro: Editora Fiocruz, 1998.

; NASCIMENTO, D. R.; EDLER, F. C. As origens da reforma sanitária e do SUS. In: LIMA, N. T.; GERSCHMAN, S.; EDLER, F. C.; SUÁREZ, J. M. (Org.). Saúde e democracia: história e perspectivas do SUS. Rio de Janeiro: Fiocruz, 2005. p. 59-81.

FAVARET, Ana C. et al. Estimativa do impacto da vinculação constitucional de recursos para a saúde. Cadernos de Economia da Saúde, Brasília: Editora Ministério da Saúde, série J, n. 4, 2001.

FLEURY, Sonia (Org.). Saúde e democracia: a luta do CEBES. São Paulo: Lemos Editoria, 1997.

. Reforma sanitária: em busca de uma teoria. São Paulo: Ed. Cortez/Abrasco, 1989.

FRIEDMAN, Milton. Capitalismo e liberdade. São Paulo: Nova Cultural, 1988.

LIMA, Nisia. T.; GERSCHMAN, Silvia; EDLER, F. C.; SUÁREZ, J. M. (Org.). Saúde e democracia: história e perspectiva do SUS. Rio de Janeiro: Editora Fiocruz, 2005.

MÉDICI, André C.; MARQUES, Rosa. M. Fundo Social de Emergência e o financiamento da política social no biênio 1994/1995. São Paulo: IESP/Fundap, maio 1994. (Notas Técnicas, n. 5).

Saúde no contexto da seguridade: dilemas de financiamento. São Paulo:

Instituto de Economia do Setor Público, Fundação do Desenvolvimento Administrativo. ago. 1995. (Nota técnica, n. 14). 
MARQUES, Rosa. O regime de acumulação sob a dominância financeira e a nova ordem no Brasil. In: MARQUES, Rosa; FERREIRA, Mariana (Org.). O Brasil sob a nova ordem: a economia brasileira contemporânea: uma análise dos governos Collor a Lula. São Paulo: Saraiva, 2009.

; MENDES, Aquilas. Financiamento: a doença crônica da saúde pública brasileira. In: ENCONTRO NACIONAL DE ECONOMIA DA SAÚDE, 5, Organizado por Ugá, M. et al. Anais... Salvador: Abres, pp. 213-237,

; UGINO, Camila Kimie. A Previdência Social: da Constituição à reforma de Lula. Revista Textos \& Contextos, Porto Alegre, v. 8, n. 2 p. 195-218, jul./dez. 2009.

2009.

; NAKATANI, Paulo. O que é capital fictício e sua crise. São Paulo: Brasiliense,

MENDES, Áquilas; MARQUES, Rosa. A saúde pública sob a batuta da nova ordem. In: MARQUES, Rosa; FERREIRA, Mariana (Org.). O Brasil sob a nova ordem: a economia brasileira contemporânea: uma análise dos governos Collor a Lula. São Paulo: Saraiva, 2009.

PAIM, Jairnilson. Bases conceituais da reforma sanitária. In: FLEURY, Sonia (Org.). Saúde e democracia: a luta do Cebes. São Paulo: Lemos Editoria, 1997.

PIOLA, Sergio. Financiamento e revisão constitucional. In: ENCONTRO NACIONAL DE ECONOMIA DA SAÚDE, 1, São Paulo, Abres, 1994.

. Financiamento da Seguridade Social e do SUS: desafios e perspectivas. In: ENCONTRO NACIONAL DE ECONOMIA DA SAÚDE, 9, Rio de Janeiro, Abres, dezembro de 2009.

; BIASOTO JR, G. Finanças e dispêndios: financiamento do SUS, gasto público e base tributária. Ipea, 2000. Mimeografado.

RIBEIRO, José Aparecido; PIOLA, Sergio; SERVO, Luciana. As novas configurações de antigos problemas: financiamento e gasto com Ações e Serviços Públicos de Saúde no Brasil. Divulgação em Saúde Para Debate. II Jornada de Economia da Saúde - Abres, Rio de Janeiro, n. 37, p. 21-43, jan. 2007.

UGÁ, Maria Alice Dominguez. Ajusta estrutural, governabilidade e democracia. In: GERCHMAN, S.; VIANNA, M. L. Werneck. A miragem da pós-modernidade. Democracia e políticas sociais no contexto da globalização. Rio de Janeiro: Fiocruz, 1997.

WORLD HEALTH ORGANIZATION. World Health Statistics 2008. WHO Press, World Health Organization, 2008. 